\title{
Antagonistic Interactions of "Ya-Sa-Marn-Phlae" Ethanol Extract in Combination with Topical Antiseptics against Clinical Isolates of Staphylococcus aureus
}

\author{
Sasitorn Chusri, ${ }^{1,2}$ Sirirat Tongrod, ${ }^{1}$ Julalak Chokpaisarn, ${ }^{2,3}$ \\ Surasak Limsuwan, ${ }^{1,2}$ and Supayang Piyawan Voravuthikunchai ${ }^{2,3}$ \\ ${ }^{1}$ Faculty of Traditional Thai Medicine, Prince of Songkla University, Hat Yai, Songkla 90110, Thailand \\ ${ }^{2}$ Natural Product Research Center of Excellence, Prince of Songkla University, Hat Yai, Songkla 90110, Thailand \\ ${ }^{3}$ Department of Microbiology, Faculty of Science, Prince of Songkla University, Hat Yai, Songkhla 90112, Thailand
}

Correspondence should be addressed to Sasitorn Chusri; sasitorn.chu@psu.ac.th

Received 5 December 2013; Revised 7 February 2014; Accepted 12 March 2014; Published 5 May 2014

Academic Editor: Paul M. Tulkens

Copyright (C) 2014 Sasitorn Chusri et al. This is an open access article distributed under the Creative Commons Attribution License, which permits unrestricted use, distribution, and reproduction in any medium, provided the original work is properly cited.

\begin{abstract}
This investigation was aimed at assessing a possible interaction of a traditional Thai herbal recipe, "Ya-Sa-Marn-Phlae (YSMP)," used for wound treatments with topical antiseptics, povidone-iodine (PI) solution and hydrogen peroxide $\left(\mathrm{H}_{2} \mathrm{O}_{2}\right)$, and effects of THRSK010 alone and the combinations on Staphylococcus aureus. Antibacterial activities of ethanol extracts from the herbal recipe were determined against both methicillin resistant Staphylococcus aureus (MRSA) and methicillin-susceptible S. aureus (MSSA). YSMP exhibited remarkable antistaphylococcal activity with MIC values of 3.9-7.8 $\mu \mathrm{g} / \mathrm{mL}$. This recipe possessed bacteriostatic activity and did not reduce the tolerance of both MRSA and MSSA isolates to the high ionic strength. Interaction between THR-SK010 and the antiseptics was carried out by checkerboard testing and time-kill assay. Both indifferent and slightly antagonistic effects were observed with THR-SK010/PI and THR-SK010/ $\mathrm{H}_{2} \mathrm{O}_{2}$ combinations against the tested isolates. In addition to commercially available antiseptics, THR-SK010 offered additional therapeutic options for the decolonization of MRSA and MSSA. Topical application of plant extracts with antioxidant activity, such as THR-SK010, should not be used immediately with PI or $\mathrm{H}_{2} \mathrm{O}_{2}$ and further investigation on this interaction is needed.
\end{abstract}

\section{Introduction}

Besides being one of the most important human pathogens, Staphylococcus aureus colonizes large proportions of human populations. Several researchers proposed that nasal cavities are considered to be the primary colonization site $[1,2]$, and $20 \%$ of the population is classified as persistent carrier while $60 \%$ is classified as intermittent carrier. Although the human throat is less well studied as a carriage site, there are some investigations reporting that the throat is the most common carriage site [3, 4]. Risk and outcome of nosocomial staphylococcal bacteraemia of $S$. aureus nasal carriers and noncarriers are significantly different and the bacteraemia is three times more frequent in the carriers than in noncarriers [5]. Approximately, $30-80 \%$ of staphylococcal infections are of endogenous origin in nasal carriers $[2,6]$. Hence, effective disinfection and antisepsis are very essential in preventing infections, particularly within health care settings.

Decolonization agents such as chlorhexidine, mupirocin, and triclosan have been used to eradicate nasal and hand carriage of methicillin-susceptible S. aureus (MSSA) and MRSA. Unfortunately, emergence of resistant isolates as a result of long-term and intermittent usage of these decolonization agents has been frequently reported [7]. Increasing effort has been focused on utilizing secondary metabolites of medicinal plants which form the backbone of traditional medicine as alternative antiseptics $[8,9]$. In addition, in vitro activities of some plant-derived compounds in combination with topical antiseptics against MRSA have been investigated for offering additional therapeutic options for the decolonization of this pathogen [10-12]. Although only little information is available for herbal recipes which are in current use by folk 
healers, some recipes from China [13], India [14], or Ghana [15] possessed interesting biological activities.

A traditional Thai herbal recipe, namely, "Ya-Sa-MarnPhlae" (YSMP or THR-SK010) was obtained from a folk healer, Mr. Somporn Chanwanisakul, and has been used for the treatment of wounds and skin infections. The ethanol extract of this recipe exhibited low toxicity and possessed antibacterial, antibiofilm, anti-inflammatory, and antioxidant activities [16-19]. In this study, we further investigated the antibacterial efficacy of THR-SK010 in combination with topical antiseptics (povidone-iodine and hydrogen peroxide) against both MRSA from infective origins and MSSA from colonization origins in order to answer whether any different effects occur between the bacteria from different sources. Effects of THR-SK010 alone and the combinations on staphylococcal cell membrane functions were additionally observed in high ionic strength environment.

\section{Material and Methods}

2.1. Extraction of "Ya-Sa-Marn-Phlae". Powdered YSMP $(500 \mathrm{~g})$ consists of equal amounts (125 g) of Curcuma longa $\mathrm{L}$. (rhizome), Areca catechu L. (seed), Oryza sativa L. (seed), and Garcinia mangostana L. (pericarp). Plant parts were locally collected and reference voucher specimens were deposited at Faculty of Traditional Thai Medicine, Prince of Songkla University, Hat Yai, Songkhla, Thailand. The powder was macerated with $95 \%$ ethanol for seven days $(1: 5 ; \mathrm{w} / \mathrm{v})$. After filtration through a Whatman number 1 filter paper, this filtrate was removed with a rotatory evaporator and kept at $55^{\circ} \mathrm{C}$ until it was completely dry. Yield of the ethanol extract that was calculated as the ratio of the weight of the extract to the weight of the crude herb powder was $6.45 \%$ $(\mathrm{w} / \mathrm{w})$. Samples were stored in a sterile screw-capped bottle at $-20^{\circ} \mathrm{C}$ and dissolved in dimethylsulfoxide (DMSO; Merck, Germany) before use [17].

2.2. Tested Bacterial Strains. Five isolates of methicillin resistant Staphylococcus aureus (MRSA) and five isolates of methicillin-susceptible Staphylococcus aureus (MSSA) obtained from the Natural Products Research Center, Faculty of Science, Prince of Songkla University, were used throughout the study. Antibiotic susceptibility and molecular characteristics of the human isolates have been reported previously [20].

2.3. Determination of Antistaphylococcal Activities of the Herbal Recipe Extract and Topical Antiseptics. Overnight suspensions of tested staphylococcal isolates were prepared following inoculation of Muller Hinton broth (MHB; Becton, Dickinson, and Company, France) with three to five wellisolated colonies from TSA. The suspension was adjusted to a $0.5 \mathrm{McF}$ arland standard $\left(1.5 \times 10^{8} \mathrm{CFU} / \mathrm{mL}\right)$ and then diluted in $\mathrm{MHB}$ to generate a final concentration of $1 \times 10^{6} \mathrm{CFU} / \mathrm{mL}$. A stock solution of the herbal recipe $(100 \mathrm{mg} / \mathrm{mL}$ in DMSO) was diluted in $\mathrm{MHB}$ to produce a working solution of $2 \mathrm{mg} / \mathrm{mL}$. Povidone-iodine (PI) solution which is an aqueous solution of $10 \%$ PI to $1 \%$ available iodine (Betadine HR,
IDS Manufacturing Ltd., Thailand) and hydrogen peroxide $\left(\mathrm{H}_{2} \mathrm{O}_{2}\right.$; Merck, Germany) were diluted in $\mathrm{MHB}$ to obtain working suspensions of $5 \%$ and $1 \%(\mathrm{v} / \mathrm{v})$, respectively. To determine the MICs of the antibacterial agents, broth microdilution assays were performed in line with CLSI guidelines [21]. Each well contained $100 \mu \mathrm{L}$ of tested antimicrobial agents (the recipe extracts $1000-0.49 \mu \mathrm{g} / \mathrm{mL}$, PI $5-2.4 \times 10^{-3}$ (\%; v/v), and $\mathrm{H}_{2} \mathrm{O}_{2} 1-4.9 \times 10^{-4}(\% ; \mathrm{v} / \mathrm{v})$ ) and $100 \mu \mathrm{L}$ of the bacterial suspension and incubated for $24 \mathrm{~h}$ at $37^{\circ} \mathrm{C}$. DMSO at final concentrations of $1 \%(\mathrm{v} / \mathrm{v})$ was employed as negative control solvent. The MIC was then determined as the lowest concentration showing no growth using optical density (OD) at $595 \mathrm{~nm}\left(\mathrm{OD}_{595 \mathrm{~nm}}\right)$ on a microplate reader (Sunrise; Tecan Group Ltd.). The assay was repeated in triplicate.

2.4. Effect of the Effective Herbal Recipe on Bacterial Halotolerance. Effect of sub-MIC (1/2xMIC), MIC, or supraMIC (2xMIC, 4xMIC, and 8xMIC) of THR-SK010 extract on the growth of representative isolates, $S$. aureus ATCC 29213, MRSA NPRC R001, and MSSA NPRC S003 on TSA and TSA supplemented with $7.5 \%(\mathrm{w} / \mathrm{v})$ sodium chloride (NaCl; Merck, Germany), was evaluated. Suspensions of the isolates prepared as described above $\left(1.5 \times 10^{8} \mathrm{CFU} / \mathrm{mL}\right.$; $1 \mathrm{~mL}$ ) were incubated with $1 \mathrm{~mL}$ of each concentration of the ethanol extract for $24 \mathrm{~h}$. An aliquot $(10 \mu \mathrm{L})$ of samples was removed and cultured onto TSA and TSA supplemented with $7.5 \% \mathrm{NaCl}$. The viable cells on TSA-NaCl and TSA were enumerated after incubation at $37^{\circ} \mathrm{C}$ for $48 \mathrm{~h} \mathrm{[22].}$

2.5. Interaction of the Effective Herbal Recipe and Antiseptics. To assess the synergistic or antagonistic activity of THR-SK010/PI and THR-SK010/ $\mathrm{H}_{2} \mathrm{O}_{2}$ combinations, fraction inhibitory concentration (FIC) was determined by chequerboard assay. In brief, serial double 2-fold dilutions of the antimicrobial compounds were prepared (the recipe extracts 2000-0.49 $\mu \mathrm{g} / \mathrm{mL}$, PI 5-2.4 × $10^{-3}\left(\%\right.$; v/v), and $\mathrm{H}_{2} \mathrm{O}_{2} 1-$ $\left.4.9 \times 10^{-4}(\% ; \mathrm{v} / \mathrm{v})\right)(2,000$ to $0.97 \mu \mathrm{g} / \mathrm{mL}$ for THR-SK010, 10 to $4.9 \times 10^{-3}(\% ; \mathrm{v} / \mathrm{v})$ for PI, and 2 to $9.8 \times 10^{-4}(\%$; $/ v)$ for $\left.\mathrm{H}_{2} \mathrm{O}_{2}\right)$. Fifty microlitres of each antiseptic was added to the rows of a 96-well microtiter plate in decreasing concentrations and $50 \mu \mathrm{L}$ of the recipe extract was added to the columns in reducing concentrations. The wells were then inoculated with $100 \mu \mathrm{L}$ of the bacterial suspension containing $1 \times 10^{6} \mathrm{CFU} / \mathrm{mL}$ and the MIC of each agent alone and in combination was determined.

2.6. Time-Kill Assay. Interaction of THR-SK010 in combination with the antiseptics against representative isolates, MRSA NPRC R001, MSSA NPRC S001, and S. aureus ATCC 29213, was additionally conducted by time-kill methodology. An aliquot of bacterial suspensions prepared as described above $\left(1 \times 10^{6} \mathrm{CFU} / \mathrm{mL} ; 1 \mathrm{~mL}\right)$ was incubated with $1 \mathrm{~mL}$ of the antibacterial agents alone, was incubated at $37^{\circ} \mathrm{C}$ with $1 \mathrm{~mL}$ of the antibacterial agents alone, the combination of THR-SK010 and PI or the combination of THR-SK010 and $\mathrm{H}_{2} \mathrm{O}_{2}$. A sample of $100 \mu \mathrm{L}$ was taken every $4 \mathrm{~h}$ up to $24 \mathrm{~h}$ and subsequently measured for the bacterial growth by reading the $\mathrm{OD}_{595 \mathrm{~nm}}$. 
TABLE 1: Fractional inhibitory concentration indices (FIC) of antimicrobial agents determined by a two-dimensional chequerboard assay against methicillin resistant Staphylococcus aureus (MRSA), methicillin-susceptible Staphylococcus aureus (MSSA), and S. aureus ATCC $29213^{\mathrm{a}}$ when combined with an effective herbal formula, THR-SK010E, and topical antiseptics (povidone-iodine; PI and hydrogen peroxide; $\left.\mathrm{H}_{2} \mathrm{O}_{2}\right)$.

\begin{tabular}{|c|c|c|c|c|}
\hline \multirow{3}{*}{ Antibacterial agents } & \multirow{3}{*}{$\Sigma F I C$ ranges } & \multicolumn{3}{|c|}{ Percentage of the tested isolated } \\
\hline & & Synergy & Indifference & Antagonism \\
\hline & & $\Sigma \mathrm{FIC} \leq 0.5$ & $0.5<\Sigma$ FIC $\leq 4$ & $\Sigma \mathrm{FIC}>4$ \\
\hline \multicolumn{5}{|l|}{ THR-SK010/PI } \\
\hline $\operatorname{MRSA}(n=5)$ & $5.00-9.00$ & & & 100 \\
\hline $\operatorname{MSSA}(n=5)$ & $2.00-5.00$ & & 80 & 20 \\
\hline \multicolumn{5}{|l|}{ THR-SK010/ $\mathrm{H}_{2} \mathrm{O}_{2}$} \\
\hline $\operatorname{MRSA}(n=5)$ & $1.05-2.53$ & & 100 & \\
\hline $\operatorname{MSSA}(n=5)$ & $0.51-2.14$ & & 100 & \\
\hline
\end{tabular}

${ }^{a} \Sigma$ FIC indices of pared combinations of THR-SK010 and povidone-iodine and THR-SK010 and $\mathrm{H}_{2} \mathrm{O}_{2}$ against S. aureus ATCC 29213 were 3.00 and 1.06 , respectively.

\section{Results and Discussion}

The MICs of $\mathrm{H}_{2} \mathrm{O}_{2}$, PI, and THR-SK010 extract for MRSA and MSSA isolates were $0.31-0.63,2 \times 10^{-3}-8 \times 10^{-3}$, and $3.9-7.8 \mu \mathrm{g} / \mathrm{mL}$, respectively. Bactericidal activity and effect of THR-SK010 extract on bacterial halotolerance were further carried out with representative isolates, MRSA NPRC R001, MSSA NPRC S003, and S. aureus ATCC 29213 (data not shown). Patterns of cell survival after treatment were similar among different isolates. Numbers of viable cells of the isolates after exposure to $1 / 2 x M I C, 1 \times M I C, 2 x M I C$, and $4 \mathrm{xMIC}$ of the extract for $24 \mathrm{~h}$ decreased $2-3 \log$ folds. The level of tested isolates was reduced by at least $5 \log$ folds after treatment with $8 x M I C$ of the extract for $24 \mathrm{~h}$. For $\mathrm{TSA}+7.5 \% \mathrm{NaCl}$, the numbers of viable cells after treatment with the extract were similar to that of TSA. This indicated that treatment with THR-SK010 extract did not affect the staphylococcal halotolerance. Osmotolerance of $S$. aureus to $\mathrm{NaCl}$ is described as its ability to maintain the structural integrity of its cytoplasmic membrane. Earlier investigations indicated that sublethal injury of microbial cell membrane caused by plant extract and plant-derived compounds may alter their permeability and affect the ability of the membrane to osmoregulate the cell adequately [22-24]. Therefore, the antistaphylococcal mechanisms of the extract may not cause any alteration to the staphylococcal cell membrane function.

Using $\Sigma F I C$ values for synergy as $\leq 0.5$ and antagonism as $>4.0$ as recommended by the American Society for Microbiology (Table 1), no synergistic interactions were observed between combinations of THR-SK010/PI and THR-SK010/ $\mathrm{H}_{2} \mathrm{O}_{2}$ when tested against staphylococcal isolates. However, a tendency for an indifferent antibacterial effect was observed with THR-SK010/PI combination against MSSA isolates and THR-SK010/ $\mathrm{H}_{2} \mathrm{O}_{2}$ against both MRSA and MSSA isolates and THR-SK010/PI combination against MRSA isolates which exhibited an antagonistic antibacterial effect.

The combinations were further evaluated in bacterial growth inhibition patterns using a time-kill method as previously described with a slight modification (Figure 1).
THR-SK010 extract, PI, and $\mathrm{H}_{2} \mathrm{O}_{2}$ at 1 xMIC and 2xMIC demonstrated significant in vitro bacterial growth inhibition for $24 \mathrm{~h}$. Antagonism was noted between the recipe and PI combination. Although bacterial growth inhibitions of this combination against MRSA, MSSA, and S. aureus ATCC 29213 were observed, a regrowth of these isolates within $20 \mathrm{~h}$ was detected. Moreover, treatment with 1xMIC of the combination of the recipe and $\mathrm{H}_{2} \mathrm{O}_{2}$ caused regrowth of the isolates after $12 \mathrm{~h}$.

This investigation shows for the first time (to our knowledge) that the Thai herbal recipe may not work effectively in combination with topical antiseptics as shown by their antagonistic effects against multidrug resistant bacteria. Commercially available antiseptics, PI and $\mathrm{H}_{2} \mathrm{O}_{2}$, were chosen for their remarkable antistaphylococcal activity against both planktonic and biofilm growth modes [25-27] and their rapid action against bacteria [28]. According to the FIC indices in the present study, the combination of THR-SK010 and $\mathrm{H}_{2} \mathrm{O}_{2}$ or THR-SK010 and PI exerted indifferent antibacterial activity against most of the tested isolates. Observation of the bacterial growth inhibition patterns in the presence of each antibacterial agent and in the presence of the combinations was additionally performed. Slightly antagonistic effects were detected in these combinations. It is well established that the antibacterial activity of PI is due to the slow release of iodine, which shows a potent oxidative activity. Similarly, $\mathrm{H}_{2} \mathrm{O}_{2}$ is thought to kill bacteria by rapidly damaging DNA with highly reactive hydroxyl radicals [28]. Therefore, compounds with antioxidant activity are expected to reduce the efficacy or inhibit the activity of PI and $\mathrm{H}_{2} \mathrm{O}_{2}$. Interferences of the biological activities of the antiseptics including their antibacterial activity have been found from both chemicals such as sodium thiosulfate [29] and plant-derived compounds such as quercetin [30] and catechins [31]. The herbal components of THR-SK010, curcuminoids from Curcuma longa [32], and xanthones from Garcinia mangostana [33] possessed strong antioxidant activities; thus, the biological activity might have an inhibitory effect on the antibacterial activity of PI and $\mathrm{H}_{2} \mathrm{O}_{2}$. 


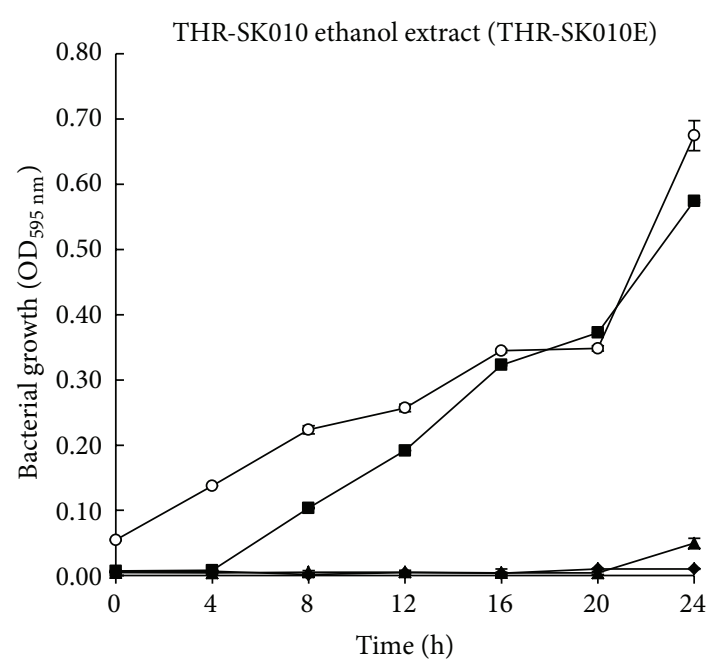

(a)

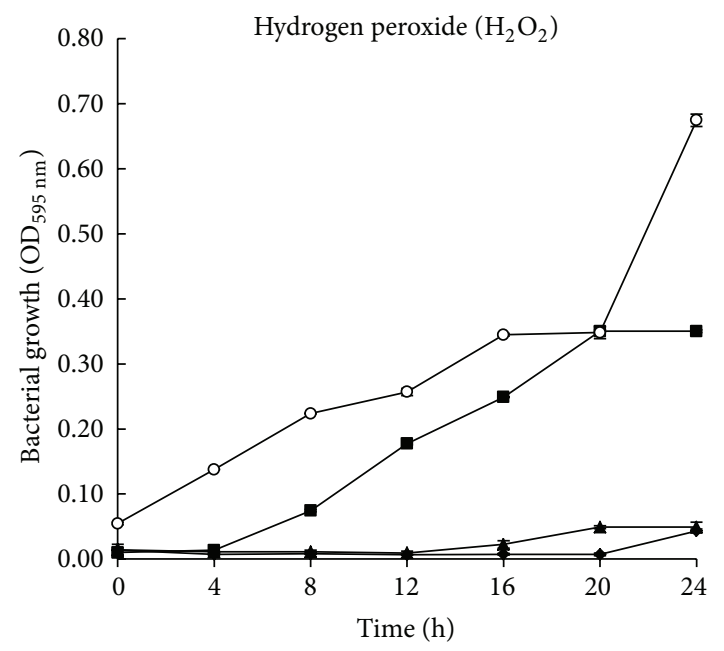

(c)

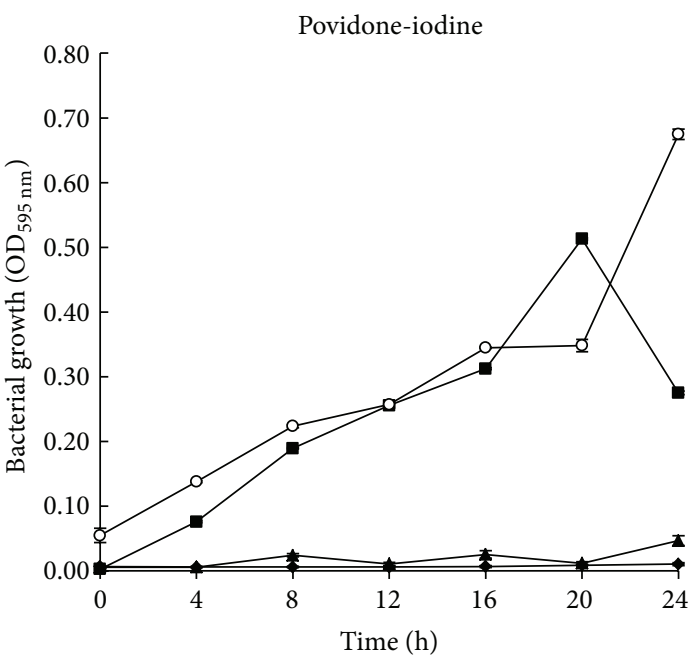

(b)

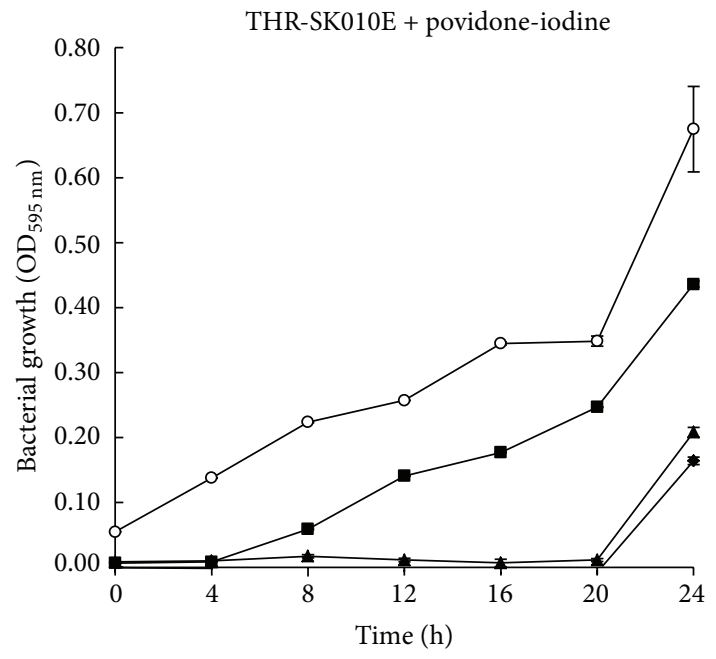

(d)

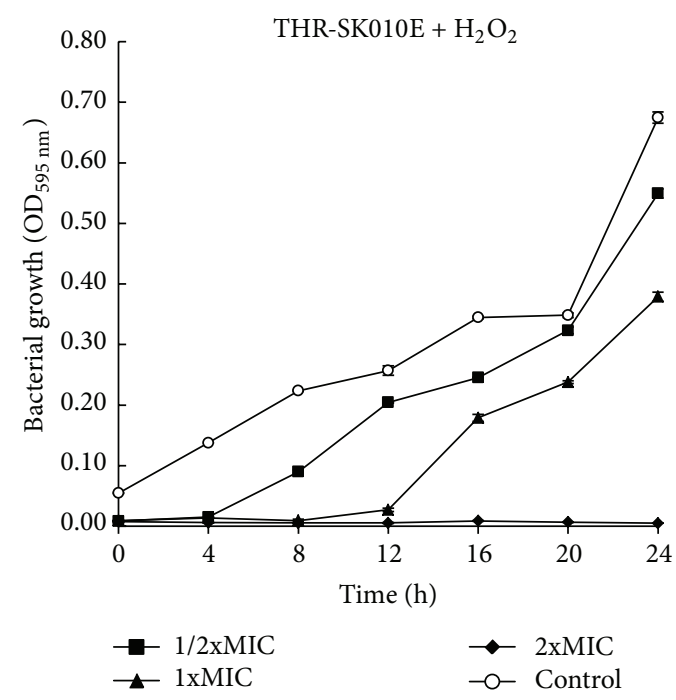

(e)

FIGURE 1: Bacterial growth inhibition patterns of THR-SK010 ethanol extract (a), povidone-iodine (PI; (b)), and hydrogen peroxide $\left(\mathrm{H}_{2} \mathrm{O}_{2}\right.$; (c)) and combinations of THR-SK010/PI (d) and THR-SK010/ $\mathrm{H}_{2} \mathrm{O}_{2}$ (e) against methicillin resistant Staphylococcus aureus NPRC R001. Minimum inhibitory concentration (MIC) values of THR-SK010E, $\mathrm{H}_{2} \mathrm{O}_{2}$, and PI were $3.9,4 \times 10^{-3}$, and $0.63 \mu \mathrm{g} / \mathrm{mL}$, respectively. 


\section{Conclusion}

In summary, our data revealed that traditional Thai herbal recipe THR-SK010 possessed notable antibacterial activity against both MRSA and MSSA. The recipe exhibited bacteriostatic activity and did not affect the halotolerance of the pathogen. Our findings indicate that the topical recipe reduces the antibacterial activity of both $\mathrm{PI}$ and $\mathrm{H}_{2} \mathrm{O}_{2}$ which is probably due to the antioxidant activity of its herbal components.

\section{Conflict of Interests}

The authors declared that there was no conflict of interests.

\section{Acknowledgments}

This work was supported by the grants from The Agricultural Research Development Agency (Public Organization) (no. CRP5605010130). The authors are thankful to Miss Stefania Vignotto for editing the paper.

\section{References}

[1] J. Kluytmans, A. van Belkum, and H. Verbrugh, "Nasal carriage of Staphylococcus aureus: epidemiology, underlying mechanisms, and associated risks," Clinical Microbiology Reviews, vol. 10, no. 3, pp. 505-520, 1997.

[2] C. von Eiff, K. Becker, K. Machka, H. Stammer, and G. Peters, "Nasal carriage as a source of Staphylococcus aureus bacteremia," The New England Journal of Medicine, vol. 344, no. 1, pp. 11-16, 2001.

[3] A. Hamdan-Partida, T. Sainz-Espunes, and J. Bustos-Martinez, "Characterization and persistence of Staphylococcus aureus strains isolated from the anterior nares and throats of healthy carriers in a Mexican community," Journal of Clinical Microbiology, vol. 48, no. 5, pp. 1701-1705, 2010.

[4] P. Nilsson and T. Ripa, "Staphylococcus aureus throat colonization is more frequent than colonization in the anterior nares," Journal of Clinical Microbiology, vol. 44, no. 9, pp. 3334-3339, 2006.

[5] H. F. Wertheim, M. C. Vos, A. Ott et al., "Risk and outcome of nosocomial Staphylococcus aureus bacteraemia in nasal carriers versus non-carriers," The Lancet, vol. 364, no. 9435, pp. 703-705, 2004.

[6] C. Luedicke, P. Slickers, R. Ehricht, and S. Monecke, "Molecular fingerprinting of Staphylococcus aureus from bone and joint infections," European Journal of Clinical Microbiology and Infectious Diseases, vol. 29, no. 4, pp. 457-463, 2010.

[7] A. Kali, S. Stephen, S. Umadevi, S. Kumar, N. M. Joseph, and S. Srirangaraj, "Changing trends in resistance pattern of methicillin resistant Staphylococcus aureus," Journal of Clinical and Diagnostic Research, vol. 7, no. 9, pp. 1979-1982, 2013.

[8] S. D. Cox, C. M. Mann, and J. L. Markham, "Interactions between components of the essential oil of Melaleuca alternifolia," Journal of Applied Microbiology, vol. 91, no. 3, pp. 492-497, 2001.

[9] J. M. Wilkinson and H. M. Cavanagh, "Antibacterial activity of essential oils from Australian native plants," Phytotherapy Research, vol. 19, no. 7, pp. 643-646, 2005.
[10] M. Ansari, K. Larijani, and M. Saber-Tehrani, "Antibacterial activity of Lippa citriodora herb essence against MRSA Staphylococcus aureaus," African Journal of Microbiology Research, vol. 6, no. 1, pp. 16-19, 2012.

[11] E. R. Hendry, T. Worthington, B. R. Conway, and P. A. Lambert, "Antimicrobial efficacy of eucalyptus oil and 1,8-cineole alone and in combination with chlorhexidine digluconate against microorganisms grown in planktonic and biofilm cultures," Journal of Antimicrobial Chemotherapy, vol. 64, no. 6, pp. 12191225, 2009.

[12] K. L. LaPlante, "In vitro activity of lysostaphin, mupirocin, and tea tree oil against clinical methicillin-resistant Staphylococcus aureus," Diagnostic Microbiology \& Infectious Disease, vol. 57, no. 4, pp. 413-418, 2007.

[13] J. C. Tam, K. M. Lau, C. L. Liu et al., "The in vivo and in vitro diabetic wound healing effects of a 2-herb formula and its mechanisms of action," Journal of Ethnopharmacology, vol. 134, no. 3, pp. 831-838, 2011.

[14] A. Gupta, N. K. Upadhyay, R. C. Sawhney, and R. Kumar, "A poly-herbal formulation accelerates normal and impaired diabetic wound healing," Wound Repair and Regeneration, vol. 16, no. 6, pp. 784-790, 2008.

[15] C. Agyare, A. Asase, M. Lechtenberg, M. Niehues, A. Deters, and A. Hensel, "An ethnopharmacological survey and in vitro confirmation of ethnopharmacological use of medicinal plants used for wound healing in Bosomtwi-Atwima-Kwanwoma area, Ghana," Journal of Ethnopharmacology, vol. 125, no. 3, pp. 393403, 2009.

[16] S. Chusri, W. Jittanon, K. Maneenoon, and S. P. Voravuthikunchai, "An effective antibiofilm agent against Pseudomonas aeruginosa biofilm from traditional Thai herbal recipes used for wound treatments," Microbial Drug Resistance, vol. 19, no. 5, pp. 337-343, 2013.

[17] S. Chusri, S. Settharaksa, J. Chokpaisarn, S. Limsuwan, and S. P. Voravuthikunchai, "Thai herbal formulas used for wound treatment: a study of their antibacterial potency, anti-inflammatory, antioxidant, and cytotoxicity effects," The Journal of Alternative and Complementary Medicine, vol. 19, no. 7, pp. 671-676, 2013.

[18] S. Chusri, K. Sompetch, S. Mukdee et al., "Inhibition of Staphylococcus epidermidis biofilm formation by traditional Thai herbal recipes used for wound treatment," Evidence-Based Complementary and Alternative Medicine, vol. 2012, Article ID 159797, 8 pages, 2012.

[19] S. Chusri, N. Chaicoch, W. Thongza-Ard, S. Limsuwan, and S. P. Voravuthikunchai, "In vitro antibacterial activity of ethanol extracts of nine herbal formulas and its plant components used for skin infections in Southern Thailand," Journal of Medicinal Plants Research, vol. 6, pp. 5616-5623, 2012.

[20] N. Indrawattana, O. Sungkhachat, N. Sookrung et al., "Staphylococcus aureus clinical isolates: antibiotic susceptibility, molecular characteristics, and ability to form biofilm," BioMed Research International, vol. 2013, Article ID 314654, 11 pages, 2013.

[21] CLSI, M07-A9-Methods for Dilution Antimicrobial Susceptibility Tests for Bacteria That Grow Aerobically, vol. 32, no. 2, Clinical and Laboratory Standards Institute, Wayne, Pa , USA, 9th edition, 2012.

[22] S. Chusri and S. P. Voravuthikunchai, "Damage of staphylococcal cytoplasmic membrane by Quercus infectoria G. Olivier and its components," Letters in Applied Microbiology, vol. 52, no. 6, pp. 565-572, 2011.

[23] C. F. Carson, B. J. Mee, and T. V. Riley, "Mechanism of action of Melaleuca alternifolia (tea tree) oil on Staphylococcus aureus 
determined by time-kill, lysis, leakage, and salt tolerance assays and electron microscopy," Antimicrobial Agents and Chemotherapy, vol. 46, no. 6, pp. 1914-1920, 2002.

[24] E. L. de Souza, J. C. de Barros, C. E. V. de Oliveira, and M. L. da Conceicao, "Influence of Origanum vulgare L. essential oil on enterotoxin production, membrane permeability and surface characteristics of Staphylococcus aureus," International Journal of Food Microbiology, vol. 137, no. 2-3, pp. 308-311, 2010.

[25] C. Block, E. Robenshtok, A. Simhon, and M. Shapiro, "Evaluation of chlorhexidine and povidone iodine activity against methicillin-resistant Staphylococcus aureus and vancomycinresistant Enterococcus faecalis using a surface test," Journal of Hospital Infection, vol. 46, no. 2, pp. 147-152, 2000.

[26] K. Chaieb, T. Zmantar, Y. Souiden, K. Mahdouani, and A. Bakhrouf, "XTT assay for evaluating the effect of alcohols, hydrogen peroxide and benzalkonium chloride on biofilm formation of Staphylococcus epidermidis," Microbial Pathogenesis, vol. 50, no. 1, pp. 1-5, 2011.

[27] E. Presterl, M. Suchomel, M. Eder et al., "Effects of alcohols, povidone-iodine and hydrogen peroxide on biofilms of Staphylococcus epidermidis," Journal of Antimicrobial Chemotherapy, vol. 60, no. 2, pp. 417-420, 2007.

[28] P. A. Lio and E. T. Kaye, “Topical antibacterial agents," Infectious Disease Clinics of North America, vol. 23, no. 4, pp. 945-963, 2009.

[29] M. Sano, R. Yoshida, M. Degawa, T. Miyase, and K. Yoshino, "Determination of peroxyl radical scavenging activity of flavonoids and plant extracts using an automatic potentiometric titrator," Journal of Agricultural and Food Chemistry, vol. 51, no. 10, pp. 2912-2916, 2003.

[30] K. Min and S. E. Ebeler, "Quercetin inhibits hydrogen peroxideinduced DNA damage and enhances DNA repair in Caco-2 cells," Food and Chemical Toxicology, vol. 47, no. 11, pp. 27162722, 2009.

[31] Y. Tayama, K. Miyake, K. Sugihara et al., "Effect of green tea beverages on efficacy of povidone-iodine," Journal of Health Science, vol. 52, no. 3, pp. 324-328, 2006.

[32] A. J. Ruby, G. Kuttan, K. D. Babu, K. N. Rajasekharan, and R. Kuttan, "Anti-tumour and antioxidant activity of natural curcuminoids," Cancer Letters, vol. 94, no. 1, pp. 79-83, 1995.

[33] H.-A. Jung, B. N. Su, W. J. Keller, R. G. Mehta, and A. D. Kinghorn, "Antioxidant xanthones from the pericarp of Garcinia mangostana (Mangosteen)," Journal of Agricultural and Food Chemistry, vol. 54, no. 6, pp. 2077-2082, 2006. 

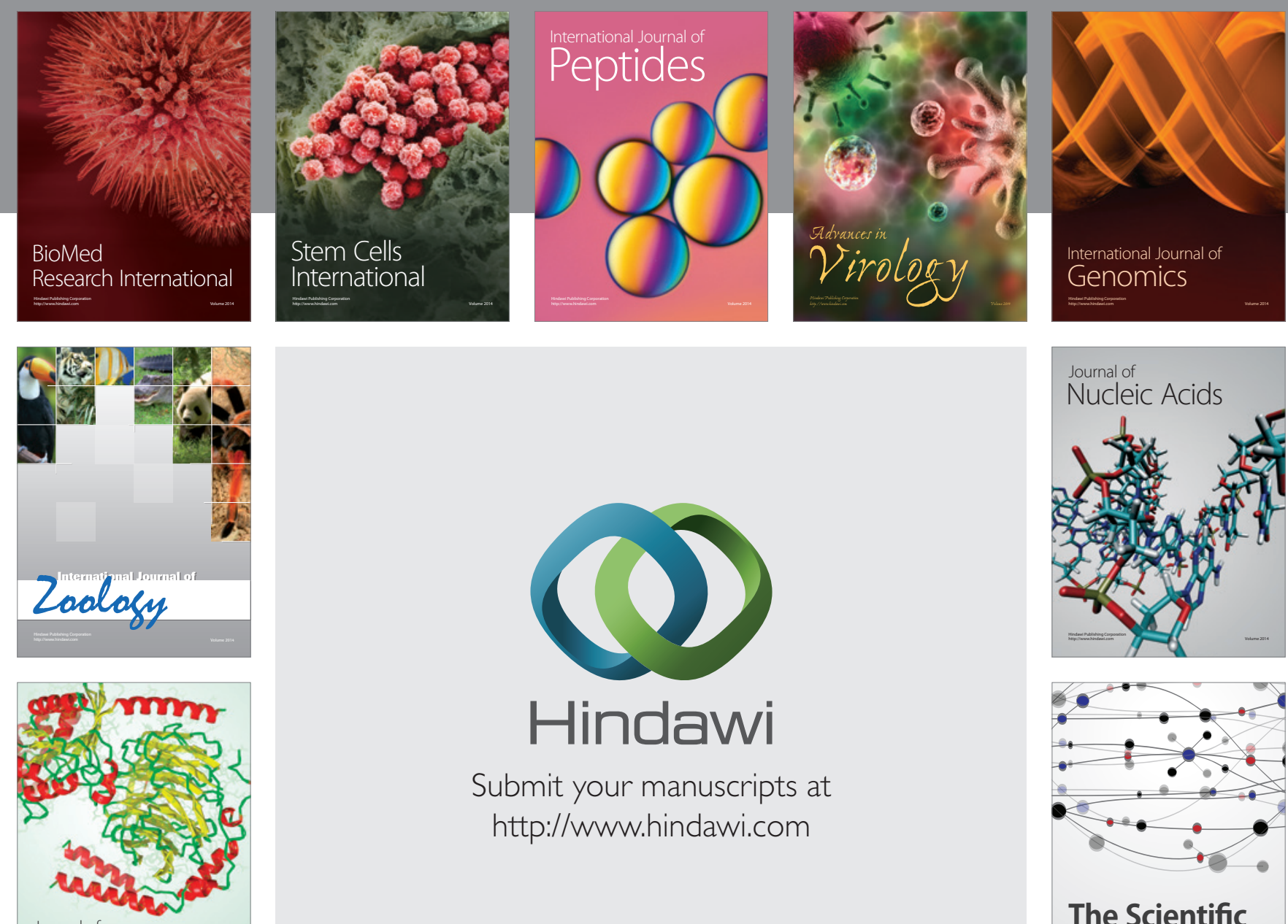

Submit your manuscripts at

http://www.hindawi.com

Journal of
Signal Transduction
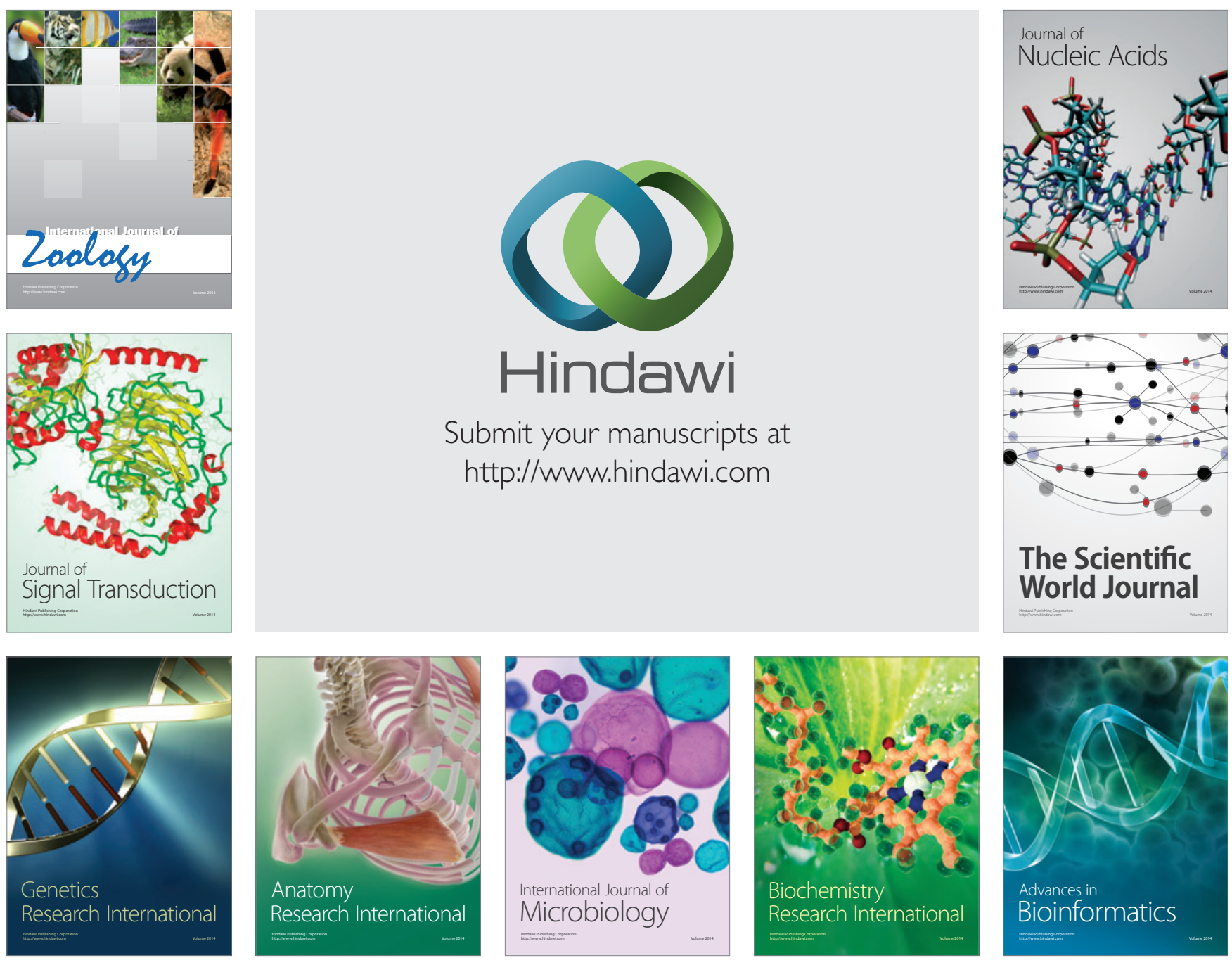

The Scientific World Journal
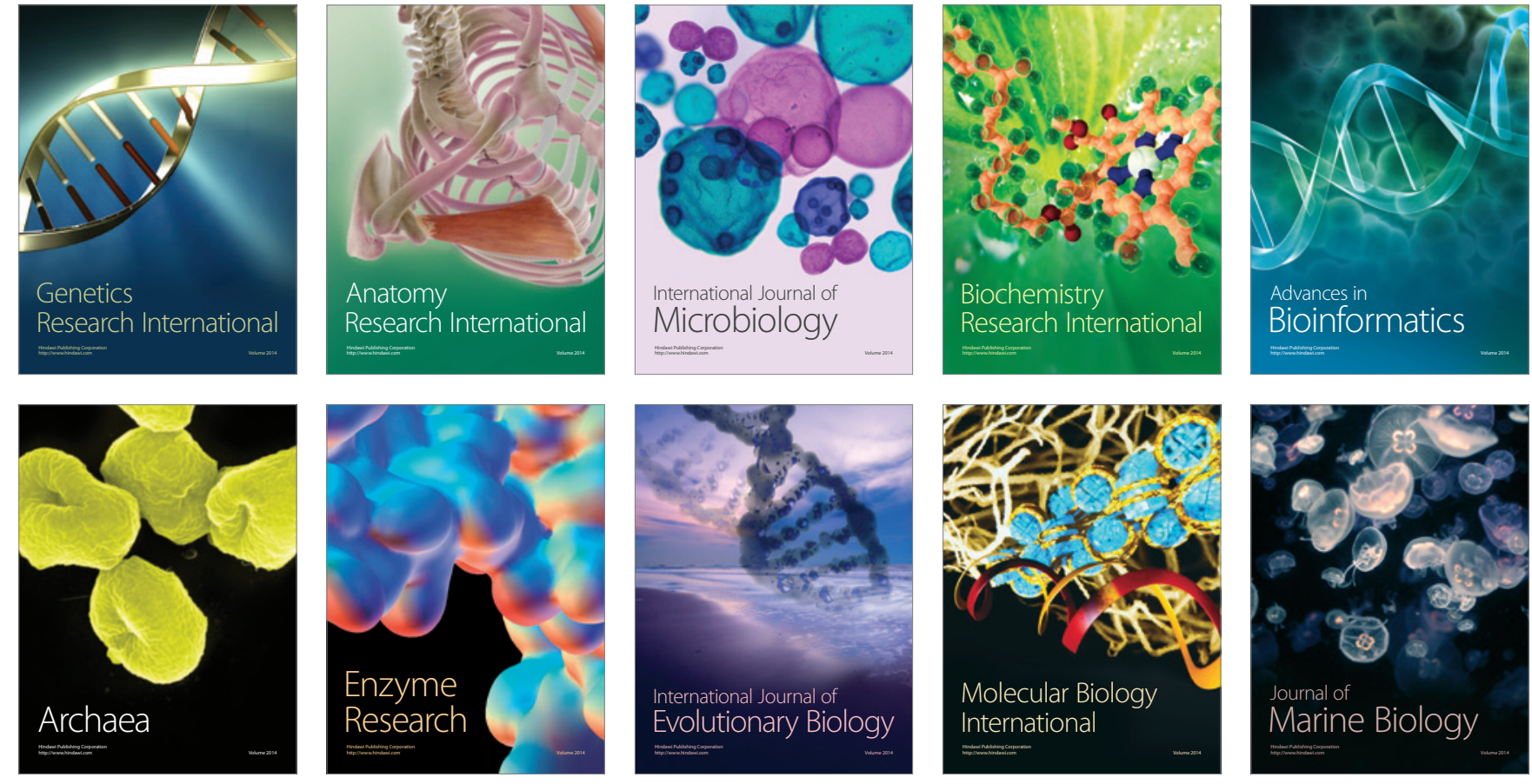